\title{
Adherence to dietary recommendations in diabetes mellitus: disease acceptance as a potential mediator
}

This article was published in the following Dove Press journal:

Patient Preference and Adherence

\author{
Mariusz Jaworski ${ }^{1}$ \\ Mariusz Panczyk' \\ Małgorzata Cedro ${ }^{2}$ \\ Alicja Kucharska ${ }^{3}$ \\ 'Division of Teaching and Outcomes \\ of Education, Faculty of Health \\ Sciences, Medical University of \\ Warsaw, Warsaw, Poland; ${ }^{2}$ Faculty of \\ Health Sciences, Medical University of \\ Warsaw, Warsaw, Poland; ${ }^{3}$ Department \\ of Human Nutrition, Faculty of \\ Health Sciences, Medical University \\ of Warsaw, Warsaw, Poland
}

\begin{abstract}
Background: Adherence by diabetic patients to dietary recommendations is important for effective therapy. Considering patients' expectations in case of diet is significant in this regard. The aim of this paper was to analyze the relationship between selected independent variables (eg, regular blood glucose testing) and patients' adherence to dietary recommendations, bearing in mind that the degree of disease acceptance might play a mediation role.
\end{abstract}

Subjects and methods: A cross-sectional study was conducted in 91 patients treated for type 2 diabetes mellitus in a public medical facility. Paper-and-pencil interviewing was administered ahead of the planned visit with a diabetes specialist. Two measures were applied in the study: the Acceptance and Action Diabetes Questionnaire and the Patient Diet Adherence in Diabetes Scale. Additionally, data related to sociodemographic characteristics, lifestyle-related factors, and the course of the disease (management, incidence of complications, and dietician's supervision) were also collected. The regression method was used in the analysis, and Cohen's methodology was used to estimate partial mediation. Significance of the mediation effect was assessed by the Goodman test. $P$-values of $<0.05$ were considered statistically significant

Results: Patients' non-adherence to dietary recommendations was related to a low level of disease acceptance (standardized regression coefficient $=-0.266 ; P=0.010$ ). Moreover, failure to perform regular blood glucose testing was associated with a lack of disease acceptance ( standardized regression coefficient $=-0.455 ; P=0.000$ ). However, the lack of regular blood glucose testing and low level of acceptance had only partially negative impacts on adherence to dietary recommendations (Goodman mediation test, $Z=1.939 ; P=0.054$ ). This dependence was not seen in patients treated with diet and concomitant oral medicines and/or insulin therapy.

Conclusion: Effective dietary education should include activities promoting a more positive attitude toward the disease. This may be obtained by individual counseling, respecting the patient's needs, and focus on regular blood glucose testing.

Keywords: patient adherence, diabetes mellitus type 2, attitude toward health, glycemic control

\section{Introduction}

Type 2 diabetes mellitus is a diet-dependent disease requiring multidirectional and multidisciplinary management. ${ }^{1}$ Global epidemiology data suggest that the incidence of diabetes is increasing, and the disease affects younger and younger individuals. ${ }^{2}$ Therefore, an attempt to develop efficient prevention and treatment of the disease is one of the most vital actions to be taken in this area. ${ }^{3,4}$

Pharmacotherapy is not the sole method of treating type 2 diabetes mellitus; significant changes to the patient's lifestyle with respect to dietary habits and regular physical activity are also required. ${ }^{5}$ In fact, lifestyle change is the most difficult and problematic part of the treatment. Many patients tend to follow medical and dietary recommendations selectively. ${ }^{6}$
Correspondence: Mariusz Panczyk Division of Teaching and Outcomes of Education, Faculty of Health Sciences, Medical University of Warsaw, Zwirki i Wigury 61, Warsaw 02-09I, Poland $\mathrm{Tel}+48225720490$

Fax +48 22572 0491

Email mariusz.panczyk@wum.edu.pl $\mathrm{BY}$
hC hereby accept the Terms. Non-commercial uses of the work are permitted without any further permission from Dove Medict
for commercial use of this work, please see paragraphs 4.2 and 5 of our Terms (https://www.dovepress.com/terms.php). 
Some studies emphasize that diabetic patients become more actively involved in the therapeutic process after suffering from medical complications resulting from untreated diabetes or the development of concurrent diseases, since the patient can no longer deny his or her own disease. ${ }^{6,7}$ Underestimation of the patient's disease can be attributed to the lack of perceived negative consequences of the disease and, in turn, can trigger numerous defense mechanisms. Such defense mechanisms include unconscious personal beliefs, which seek to prevent the perception of negative emotional states and protect the patient's personality. ${ }^{8}$ In other words, the patient may think that his or her lack of "perception" of negative disease effects and good well-being are justification for not changing his or her usual lifestyle. This behavior can be reinforced by splitting, which is based on the assumption that if the patient rejects the disease diagnosis, the disease will vanish. As a result, the patient unconsciously takes actions that worsen the course of the disease. ${ }^{9}$

Available data suggest that diabetic patients often find it problematic to introduce changes in their diet. ${ }^{6}$ In most cases, new recommendations (including reduced consumption of foodstuffs containing monosaccharides and saturated fatty acids and introduction of low-glycemic products to the diet) differ considerably from the patient's current diet. Therefore, the help of a dietician is necessary to point out efficient methods of gaining new dietary habits. ${ }^{9-11}$

There have been attempts to determine the psychosocial factors that might influence effective adherence to medical recommendations in diabetic patients described in the literature. ${ }^{12-14}$ The patient's appropriate attitude toward the disease is of particular significance in this context. Health psychology defines the attitude toward a disease in three dimensions: cognitive (the patient's knowledge about the disease and treatment process), emotional (emotions the patient experiences regarding the disease), and behavioral (actions taken by the patient with respect to the disease and treatment process). These three dimensions interact with each other. ${ }^{15} \mathrm{~A}$ positive attitude toward treatment and health can promote more effective adherence to medical and dietary recommendations in a diabetic patient. Blood glucose testing, aimed at normalization of serum glucose levels, is also important for the effectiveness of treatment in diabetic patients. A controlled serum glucose level is an indication of the correct course of treatment. In other words, a patient with a positive attitude toward his or her disease should be more systematic in blood glucose testing than a patient with a negative attitude. ${ }^{16}$

Several papers have been published on psychological, social, and medical factors related to adherence of diabetic patients to medical recommendations. ${ }^{6,79,17}$ Nevertheless, only a few studies have analyzed the relationship between the attitude toward the disease and following the dietary recommendations by diabetic patients. ${ }^{14,16,18}$ A considerably greater number of studies have analyzed the relationship between psychological factors and adherence to dietary recommendations. ${ }^{6-8,12,17}$ Also, there are no papers researching the role of mediating factors in this relationship, where they are related directly to the treatment of diabetic patients. Therefore, the aim of this paper was to analyze the relationship between selected independent variables (eg, blood glucose testing, occurrence of complications, and doing enough physical activity) and the level of the patient's compliance with dietary recommendations, considering the mediation role of the patient's level of disease acceptance.

\section{Subjects and methods Subjects}

This crossover study took place in March and April 2016. Subjects $(\mathrm{n}=91)$ were recruited from among patients of the Diabetology and Internal Medicine Clinic and the Internal Medicine and Endocrinology Clinic of the Independent Public Central Clinical Hospital in Warsaw (convenience sample). The study included patients with type 2 diabetes mellitus diagnosed at least 6 months prior to enrollment, who were under the constant supervision of a diabetology outpatient clinic, received education on diet and blood glucose testing, and were aged 35-70 years. Patients with other types of diabetes, with a disease duration shorter than 6 months, non-educated about diet and blood glucose testing, not supervised by a diabetology outpatient clinic, bedridden, or under guardianship were excluded from participation in the study. Detailed characteristics of the study group are listed in Table 1.

Data were collected by applying a paper-and-pencil personal interview by specially trained interviewers. Interviews took place before scheduled visits to a diabetes specialist and were not limited in time. The collected data were anonymized and digitized for further stages of analysis.

\section{Ethics statement}

The authors sought approval from the Ethics Committee of the Medical University of Warsaw to conduct this study. According to the Ethics Committee, "non-interventional studies do not require the opinion of the Ethics Committee in accordance with Art. 37 al of the Pharmaceutical Law Act (Journal of Laws of 2001, No 126, item 1381)".

All patients provided verbal informed consent to participate in this research. The objective of the study and its 
Table I Characteristics of the study group

\begin{tabular}{ll}
\hline Characteristics & \\
\hline Age (mean \pm SD) & $55.2 \pm 11.57$ years \\
Body mass index (mean \pm SD) & $32.05 \pm 6.762 \mathrm{~kg} / \mathrm{m}^{2}$ \\
Duration of diabetes (mean \pm SD) & $9.9 \pm 8.18$ years \\
Number of complications (median) & 2.0 \\
Sex, $\mathrm{n}(\%)$ & \\
$\quad$ Female & $53(58.2)$ \\
$\quad$ Male & $38(41.8)$ \\
Education, $\mathrm{n}(\%)$ & \\
$\quad$ Basic & $5(5.6)$ \\
Vocational & $20(22.2)$ \\
Secondary & $41(45.5)$ \\
Higher & $24(26.7)$ \\
Place of residence, $\mathrm{n}(\%)$ & $16(17.6)$ \\
Rural area & $10(11.0)$ \\
Town of up to 20,000 inhabitants & $15(16.5)$ \\
Town of $20,000-100,000$ inhabitants & $50(54.9)$ \\
City/town of $>$ I00,000 inhabitants & \\
Monthly income, $\mathrm{n}(\%)$ & $36(42.3)$ \\
$<1,200$ PLN & $31(36.5)$ \\
I,200-2,500 PLN & $13(15.3)$ \\
$2,50 \mathrm{I}-4,000$ PLN & $5(5.9)$ \\
$>4,000$ PLN &
\end{tabular}

Note: ${ }^{a}$ Household monthly income per person (I PLN 0.28 USD). Abbreviation: PLN, Polish zloty.

anonymity throughout the research process and the voluntary nature of participation were explained to the participants face to face. The participants were also informed that the study was a research study only and that the findings were to be limited to research purposes only. Information about the details of the study, data collection and analysis, names of the researchers, and their contact information were also presented.

\section{Theoretical model}

According to the American Diabetes Association and the International Diabetes Federation, ${ }^{1,2}$ diabetes therapy is multidirectional. This treatment includes self-monitoring of blood glucose (SMBG), physical activity, and dietary recommendations. The aim of these activities is associated with the reduction of developing diabetic complications. In the literature, there is also evidence stressing that SMBG correlates with adherence to dietary recommendations by diabetic patients. ${ }^{16,17}$ In this case, the patient's attitudes toward treatment may also be important. ${ }^{16}$ According to the theoretical model, the attitude toward a disease has three important dimensions: cognitive, emotional, and behavioral. These three dimensions interact with each other. ${ }^{15}$ For this reason, the level of disease acceptance should influence not only behavior (eg, adherence to dietary recommendations or SMBG), but also cognitive aspects (eg, knowledge about the role of SMBG, physical activity, and dietary recommendations in effective diabetes therapy). Therefore, a theoretical model could be proposed. This model will take into account the disease acceptance level as a mediator between adherence to dietary recommendations and selected medical and lifestyle variables (Figure 1).

\section{Methods}

To measure acceptance of diabetes, the applied Acceptance and Action Diabetes Questionnaire (AADQ) modified by Schmitt et $\mathrm{al}^{18}$ was translated into Polish by two independent bilingual translators, with subsequent back-translation. The Polish version of the AADQ was characterized by good internal consistency (Cronbach's $\alpha=0.667$ ) and unidimensionality (self-value of the first item was 2.32 , and explained $~ 40 \%$ of the total variance).

Subjects rated the extent of their engagement in several diabetes nonacceptance behaviors using a 5-point Likert scale (from $1=$ "never" to $5=$ "almost always"). Item scores were summed, and higher values indicated a greater extent

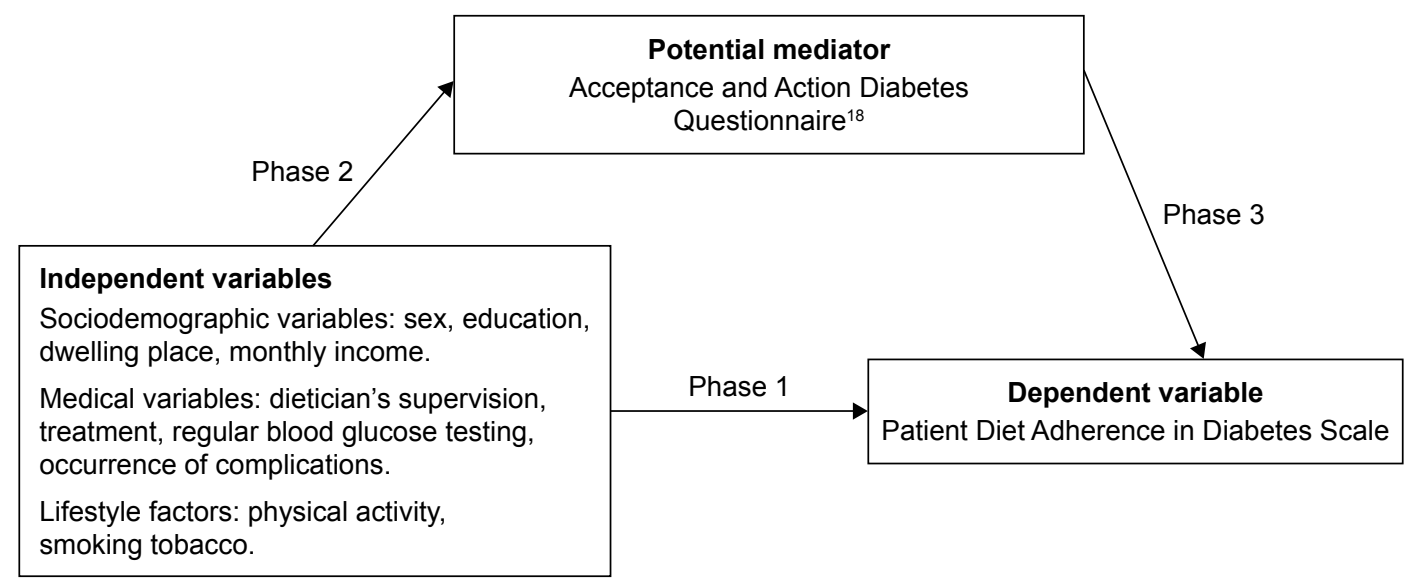

Figure I Mediation analysis for the developed model. 
of nonacceptance. Raw scores were transformed to sten scores (ie, results normalized to obtain the mean of 5.5 and SD of 2).

To assess the degree of adherence to dietary recommendations in diabetes, the authors applied an original scale developed on the basis of the 2015 Polish Diabetes Association guidelines ${ }^{19}$ and prepared by a scientific committee composed of members of the European Association for the Study of Diabetes. A list of 20 behaviors was derived from the above-described guidelines, as well as from the 2016 Standards of Medical Care Diabetes developed by the American Diabetes Association ${ }^{1}$ and standards of the Academy of Nutrition and Dietetics Nutrition Practice Guideline for Type 1 and Type 2 Diabetes in Adults. ${ }^{20}$ The list was initially subjected to two independent adjudications (by a diabetes specialist and a specialized dietitian). Having considered the remarks formed upon adjudication, the final version of the Patient Diet Adherence in Diabetes (PDAD) scale, as provided Figure S1, was obtained. One point was granted for each behavior in line with the dietary recommendations (Table 2). The maximum possible number of points was 20 . Initial analysis of psychometric properties of the PDAD indicated that the internal consistency reached 0.642 , and the scale was not

Table 2 Scored dietary behaviors in the patient diet adherence in diabetes

\begin{tabular}{ll}
\hline Recommendation & Adherence to \\
& recommendation \\
\hline Number of meals & $4-6$ \\
Times of meals & Fixed \\
Pauses between meals & $3-4$ hours \\
Using sugar/honey to & No \\
sweeten soft drinks & \\
Most frequently selected products & \\
Bread & Whole grain \\
Groats & Coarsely cut (buckwheat, pearl \\
& barley), whole grain pasta, \\
& brown rice, cooked al dente \\
Milk and milk products & With reduced fat content \\
Meat and meat products & Poultry, poultry cold cuts \\
Cooking fats & Plant oils (rapeseed oil, olive oil) \\
Fat spreads & Soft margarines \\
Recommended frequency of product consumption \\
Vegetables & Several times a day \\
Fruits & Several times a day \\
Eggs & Up to four times a week \\
Fish & At least once a week \\
Legumes & At least once a week \\
Sweets & Less than once a week \\
Fast food & Less than once a week \\
Water & Several times a day \\
Alcohol & Not to be consumed \\
Sweetened soft drinks & Less than once a week \\
\hline & \\
\hline &
\end{tabular}

one dimensional (the first factor clarified $<40 \%$ of the total variance). The results reflect the structure of the PDAD, with a large degree of variation in the evaluated behaviors (from physical activity through to alcohol consumption and eating habits). Moreover, the PDAD by definition does not represent a homogeneous psychological construct.

Besides the application of the above two scales, the interview was supplemented with additional questions about lifestyle and the course of the disease (Table 3). Data were used to evaluate the impact of previously mentioned features on adherence to dietary recommendations.

\section{Statistical analysis}

All statistical analyses were performed using the STATISTICA 13.1 (StatSoft $^{\odot}$, Inc.) software, licensed to the Medical University of Warsaw. $P$-values of $<0.05$ were considered statistically significant. The analysis consisted of three phases of partial mediation evaluation, in line with the assumptions described by Cohen et $\mathrm{al}^{21}$ which are based on a series of regression analyses. The ordinary least squares method was used to fit the regression model to empirical data. Standardized $(\beta)$ coefficients for regression were used to interpret the vector and significance of correlations. Independent dichotomous variables were coded as binary variables, and dummy variables were used for more categories.

A mediation analysis chart is presented in Figure 1. The first phase involved the evaluation of the impact of independent variables on the patient's score in the PDAD (dependent variable). Each independent variable was evaluated using separate regression models. In case of statistically significant

Table 3 Variables related to lifestyle and course of the disease

\begin{tabular}{ll}
\hline Variables & \\
\hline Dietitian's supervision, $\mathrm{n}(\%)$ & $7 \mathrm{I}(78.0)$ \\
$\quad$ No & $20(22.0)$ \\
$\quad$ Yes & \\
Treatment, $\mathrm{n}(\%)$ & $5 \mathrm{I}(56.0)$ \\
$\quad$ Dietary & $60(65.9)$ \\
$\quad$ Oral antidiabetics & $44(48.4)$ \\
$\quad$ Insulin & \\
Regular blood glucose testing, $\mathrm{n}(\%)$ & $19(20.9)$ \\
$\quad$ No & $72(79.1)$ \\
$\quad$ Yes & \\
Occurrence of complications, $\mathrm{n}(\%)$ & $33(36.3)$ \\
$\quad$ No & $58(63.7)$ \\
$\quad$ Yes & \\
Physical activity, $\mathrm{n}(\%)$ & $34(37.4)$ \\
$\quad$ No & $57(62.6)$ \\
Yes & \\
Smoking tobacco, $\mathrm{n}(\%)$ & $68(74.7)$ \\
$\quad$ No & $57(25.3)$ \\
Yes &
\end{tabular}


results, the variable was evaluated in the second phase. This phase involved the evaluation of independent variables and their relationship with a potential mediator (AADQ score). The third and final phase of analysis evaluated whether independent variables and the mediator influence PDAD scores. Mediation was assumed to be significant when intermediate relationships, the independent variable-mediator, and the mediator-dependent variable were statistically significant. In such cases, a result of the Goodman mediation test was employed to determine the mediation. The test assesses whether the product of nonstandardized regression coefficients for both relationships is significantly different than zero in case of a small number of observations. ${ }^{21}$

\section{Results}

\section{The relationship between disease acceptance and adherence to dietary recommendations}

The level of adherence to dietary recommendations in the study group was moderate (PDAD: 11.3 \pm 2.75 ). Similar results were obtained for the study subjects' acceptance

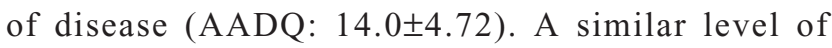
score differentiation was obtained for both instruments (variability coefficient of $36.6 \%$ vs $36.1 \%$, respectively). The results of regression analysis reveal that the lack of disease acceptance has a negative impact on the patient's adherence to dietary recommendations $\left(\beta_{\text {std }}=-0.266[95 \%\right.$ CI: $-0.469,-0.063], P=0.010)$.

\section{Mediation analysis}

The first evaluation phase of selected sociodemographic features, variables related to the course of the disease, and lifestyle revealed that only the type of treatment and regular blood glucose level testing were in a significant relationship with PDAD score (Table 4). It was observed that in patients treated with a combination of diet and oral antidiabetics $\left(\beta_{\text {std }}=0.263, P=0.012\right)$, as well as in those treated with a combination of diet and insulin $\left(\beta_{\text {std }}=0.211, P=0.045\right)$, significantly better results of adherence to dietary recommendations were achieved when compared to patients on a dietary treatment only. Also, patients who regularly tested their blood glucose levels exhibited better adherence to dietary recommendations $\left(\beta_{\mathrm{std}}=0.305, P=0.003\right)$.

The results of the second mediation analysis phase indicated that regular blood glucose level testing is the only factor in a statistically significant relationship with the potential mediator (ie, the level of the patient's acceptance of disease), as shown in Table 5. This relationship had a negative character (ie, lack of disease acceptance correlated with the lack of regular blood glucose level testing; $\beta_{\text {std }}=-0.455, P=0.001$ ).

The third and final phase involved an evaluation of the simultaneous influence of regular blood glucose testing and the mediator (AADQ score) on the extent of the patient's adherence to dietary recommendations (Table 6). It was observed that the disease acceptance level has only a minor mediation effect on the relationship between regular blood glucose testing and adherence to dietary recommendations (Goodman mediation test, $Z=1.939, P=0.054$ ).

\section{Discussion}

There are studies indicating a direct relationship between adherence to dietary recommendations and regular glycemic control. $^{22-26}$ This relationship was also demonstrated in this study. Only regular blood glucose testing is an important factor influencing adherence to dietary recommendations. Regular glycemic control is interrelated with the introduction of considerably smaller lifestyle modifications than change in the diet. In the case of diet, numerous dietary restrictions need to be introduced, such as the exclusion of certain dishes from the patient's menu that he or she truly enjoyed. ${ }^{22}$ These numerous dietary restrictions could clarify the obtained result that only about $20 \%$ of patients declared consultation with dietician. It, therefore, seems reasonable to adopt measures aiming at increasing the patient's knowledge in the field of mutual correlation of glycemic control and appropriate diet. It is particularly important in the context of the research of McElfish et $\mathrm{al}^{22}$ who emphasize that some extrinsic factors may interfere with the direct relationship between glycemic control and adherence to dietary recommendations. In their study, they pointed out the difficulties resulting from following an appropriate diet. A lack of good knowledge about recommended products and their availability on the market was the most common problem reported by participating families. A proper understanding of portion sizes was also problematic. Moreover, cultural and social barriers were one of the main obstacles in introducing the diet. Numerous subjects of the study normally do not consume products recommended for diabetic patients. It was observed that the more distant the recommended diet is from the actual habits of the patients and their family, the more difficult it is to introduce any alterations. A lack of basic understanding of primary nutrients can be another important limitation in following an appropriate diet by diabetic patients. Interestingly, it was concluded that subjects reported understanding the negative impact of carbohydrates on the development of their disease, 
Table 4 Impact of selected variables on adherence to dietary recommendations

\begin{tabular}{|c|c|c|c|c|c|c|}
\hline Tested variable & $\mathbf{b}$ & $\beta_{\text {std }}$ & $-95 \% \mathrm{Cl}$ & $+95 \% \mathrm{Cl}$ & t-statistic & $P$-value \\
\hline \multicolumn{7}{|l|}{ Sociodemographic variables } \\
\hline Intercept & 5.774 & & & & 21.027 & 0.000 \\
\hline Sex & -0.642 & -0.158 & -0.366 & 0.050 & -1.511 & 0.134 \\
\hline \multicolumn{7}{|l|}{ Female, male } \\
\hline Intercept & 5.170 & & & & $|8.29|$ & 0.000 \\
\hline Education & 0.230 & 0.057 & -0.153 & 0.268 & 0.540 & 0.590 \\
\hline \multicolumn{7}{|l|}{ Basic, vocational } \\
\hline Secondary & 0.610 & 0.180 & -0.031 & 0.391 & 1.698 & 0.093 \\
\hline Higher & 0.330 & 0.087 & -0.125 & 0.298 & 0.814 & 0.418 \\
\hline Intercept & 5.732 & & & & 22.844 & 0.000 \\
\hline Place of residence & 0.368 & 0.097 & -0.174 & 0.369 & 0.714 & 0.477 \\
\hline \multicolumn{7}{|l|}{ Rural area, town of up to 20,000 inhabitants } \\
\hline Town of $20,000-100,000$ inhabitants & 0.334 & 0.097 & -0.160 & 0.355 & 0.752 & 0.454 \\
\hline City/town of $>100,000$ inhabitants & -0.532 & -0.203 & -0.448 & 0.041 & -1.655 & 0.101 \\
\hline Intercept & 5.648 & & & & 18.944 & 0.000 \\
\hline \multicolumn{7}{|l|}{ Monthly income } \\
\hline \multicolumn{7}{|l|}{ Up to PLN I,200 } \\
\hline PLN I,20I-2,500 & 0.094 & $0.04 I$ & -0.304 & 0.386 & 0.237 & 0.813 \\
\hline PLN 2,50I-4,000 & 0.352 & 0.123 & -0.226 & 0.472 & 0.702 & 0.485 \\
\hline$>4,000$ PLN & -0.048 & -0.014 & -0.429 & $0.40 \mathrm{I}$ & -0.067 & 0.947 \\
\hline \multicolumn{7}{|l|}{ Medical variables } \\
\hline Intercept & 5.296 & & & & 22.485 & 0.000 \\
\hline Dietician's supervision & 0.954 & 0.197 & -0.009 & 0.404 & 1.899 & $0.06 \mathrm{I}$ \\
\hline Intercept & 5.455 & & & & 25.519 & 0.000 \\
\hline Dietary treatment only & 1.545 & 0.138 & $-0.07 \mid$ & 0.346 & 1.313 & 0.193 \\
\hline Intercept & 5.182 & & & & 21.552 & 0.000 \\
\hline Dietary treatment and oral antidiabetics & 1.178 & 0.263 & 0.059 & 0.466 & 2.568 & 0.012 \\
\hline Intercept & 5.366 & & & & 24.552 & 0.000 \\
\hline Dietary treatment and oral antidiabetics and insulin & 1.412 & 0.211 & 0.005 & 0.416 & 2.032 & 0.045 \\
\hline Intercept & 4.316 & & & & 9.758 & 0.000 \\
\hline Regular blood glucose testing & 1.504 & 0.305 & 0.105 & 0.506 & 3.024 & 0.003 \\
\hline Intercept & 5.606 & & & & 15.919 & 0.000 \\
\hline Presence of complications & -0.158 & -0.038 & -0.248 & 0.173 & -0.358 & 0.721 \\
\hline \multicolumn{7}{|l|}{ Lifestyle factors } \\
\hline Intercept & 5.206 & & & & 15.096 & 0.000 \\
\hline Physical activity & 0.478 & 0.116 & -0.094 & 0.325 & 1.098 & 0.275 \\
\hline Intercept & 5.529 & & & & 22.528 & 0.000 \\
\hline Smoking tobacco & -0.095 & -0.021 & -0.231 & 0.190 & -0.194 & 0.847 \\
\hline
\end{tabular}

Notes: b, regression coefficient; $\beta_{\text {std }}$, standardized regression coefficient; PLN, Polish zloty.

Table 5 Relationship between medical variables and degree of disease acceptance

\begin{tabular}{|c|c|c|c|c|c|c|}
\hline Tested variable & b & $\beta_{\text {std }}$ & $-95 \% \mathrm{Cl}$ & $+95 \% \mathrm{Cl}$ & t-statistic & $P$-value \\
\hline Intercept & 5.561 & & & & 23.042 & 0.000 \\
\hline $\begin{array}{l}\text { Dietary treatment and oral antidiabetics } \\
\text { 0: no } \\
\text { I: yes }\end{array}$ & -0.481 & -0.110 & -0.319 & 0.099 & -1.044 & 0.299 \\
\hline Intercept & 5.549 & & & & 25.926 & 0.000 \\
\hline $\begin{array}{l}\text { Dietary treatment and oral antidiabetics and insulin } \\
0: \text { no } \\
\text { I: yes }\end{array}$ & -1.215 & -0.186 & -0.393 & 0.021 & -1.786 & 0.078 \\
\hline Intercept & 7.158 & & & & 17.767 & 0.000 \\
\hline $\begin{array}{l}\text { Regular blood glucose testing } \\
\text { 0: no } \\
\text { I: yes }\end{array}$ & -2.186 & -0.455 & -0.643 & -0.268 & -4.826 & 0.000 \\
\hline
\end{tabular}

Notes: b, regression coefficient; $\beta_{\text {std }}$, standardized regression coefficient. 
Table 6 Impact of regular blood glucose testing and disease acceptance on adherence to dietary recommendations

\begin{tabular}{|c|c|c|c|c|c|c|}
\hline Tested variable & b & $\beta_{\text {std }}$ & $-95 \% \mathrm{Cl}$ & $+95 \% \mathrm{Cl}$ & t-statistic & $P$-value \\
\hline Intercept & $5.47 \mid$ & & & & 5.832 & 0.000 \\
\hline Acceptance and action diabetes & -0.161 & -0.157 & -0.381 & 0.067 & -1.395 & 0.167 \\
\hline $\begin{array}{l}\text { Regular blood glucose testing } \\
\text { 0: no } \\
\text { I: yes }\end{array}$ & 1.151 & 0.234 & 0.010 & 0.458 & 2.072 & $0.04 I$ \\
\hline
\end{tabular}

Notes: b, regression coefficient; $\beta_{\text {std }}$, standardized regression coefficient.

but they failed to realize that monosaccharides have similar effects. Therefore, it seems to be of key importance for diabetic patients to gain knowledge about diet from a dietitian or a treating physician, as well as receive support from their closest environment. It could be beneficial to discuss the difficulties resulting from the diet not only with a diabetes specialist or a dietitian, but also with the family members. The study results suggest that in the context of adherence to dietary recommendations, an adequate level of social support may play a key role. Individuals with access to various forms of social support - not only emotional, but also informative, instrumental, and others - have greater ease in dealing with the stress related to their disease. An adequate level of social support can impact the development of an appropriate and active attitude toward the disease and the ongoing treatment process ${ }^{27}$ This relates particularly to blood glucose testing. In the case of adherence to dietary recommendations, the issue is more complicated, as important psychological functions of eating have to be considered as well. ${ }^{27,28}$

Nevertheless, in this study, special regard has been given to the role of acceptance of one's own disease in the context of adherence to dietary recommendations. Patients' individual predispositions were determined to have greater influence on adherence to dietary recommendations than external factors. Naturally, social support will boost a patient's actions, but it will not bring any change on its own. Therefore, this study focuses on the role of acceptance of one's own disease, as this topic has received significantly less attention in the literature. ${ }^{28-30}$

Our results confirmed that an appropriate level of disease acceptance in patients plays a vital role in adherence to dietary recommendations. These observations are consistent with other authors' reports. ${ }^{28-30}$ It should be noted that one important paper, in particular, emphasizing the significance of patient's adequate psychological attitude, was published by DuBois et al..$^{30}$ They prepared a 12 -week positive psychology intervention for a group of 15 diabetic patients. DuBois et $\mathrm{al}^{30}$ demonstrated that adequate psychological intervention in diabetic patients was beneficial not only for their psychological functioning but also for their physical well-being. Moreover, their frequency of health behaviors increased. The psychological intervention administered also positively affected the degree of acceptance of the disease and therapeutic process in patients, and it led to their greater involvement in prophylaxis and prevention of disease development. Although the study covered a small group of subjects, the results clearly demonstrate that adequate commitment during treatment may be related to an adequate level of disease acceptance.

The mediation analysis showed a minor mediation effect of the AADQ on the relationship between regular blood glucose testing and adherence to dietary recommendations. In the discussed relation, little share of acceptance may also be connected with the fact that the level of disease acceptance does not condition adequate behavior associated with regular glycemic control and adherence to dietary recommendations. In line with the AADQ scale presented by Schmitt et al, ${ }^{18}$ low acceptance of one's own diabetes should be understood as avoidance of thinking about the disease, using the mechanism of denial, forgetting to take medication, and so on. The fact that the patient is conscious of his or her disease does not mean that he or she will take adequate and appropriate dietary measures and measures for glycemic control, the aim of which is to reduce the symptoms of the disease. It should be noted that Schmitt et al $^{18}$ stressed that a low level of diabetes acceptance is related to more frequently missed blood glucose level tests.

A minor mediation effect of the AADQ on the relationship between regular blood glucose testing and adherence to dietary recommendation may need to be considered in the context of specific characteristics of analyzed patients. All of them were under permanent control of a doctor, and $~ 20 \%$ additionally obtained dietary consultations, $63 \%$ undertook physical activity, and $>70 \%$ made use of regular glycemic control. It should be noted that these are not typical characteristics of a patient with diabetes. ${ }^{31}$ However, the group of patients studied corresponds more with the data presented by Kjome et al..$^{32}$ According to these researchers, $~ 70 \%$ of 
diabetes patients practiced SMBG, but $<50 \%$ of patients performed glucose measurements daily. An important factor that may account for such a group characteristic is recorded in the case of $64 \%$ coexisting diseases. However, in this study, it was not established that the variable - the number of complications - was linked to patients' adherence to dietary recommendations, even when taking into account an intermediary body - the degree of disease acceptance. This is an important observation, suggesting that it must not be presumed that a patient diagnosed with coexisting diseases will wish to be treated. A patient may employ the mechanism of denial. As a result of this mechanism, the patient may not see a link between his or her coexisting diseases, ill health, or complications arising out of his or her own disease.

In this study, we attempted to establish the role of one's own disease acceptance as a mediating factor between sociodemographic variables and the patient's adherence to dietary recommendations. It was established that sociodemographic variables (eg, education, place of residence, and monthly income) had no link to patients' adherence to dietary recommendations. This study showed that educational level may not be a good predictor of the patient's adherence to dietary recommendations. It also complies with reports by Al-Rasheedi ${ }^{31}$ and other authors. Moreover, our results showed that neither educational level nor sex has a relationship with adherence to dietary recommendations. In contrast, some studies have established that sex is a crucial nonmodifiable risk factor for poor diabetes management. ${ }^{33,34}$ Wong et $\mathrm{al}^{34}$ suggested that there is a significant sex difference in responsibility for meal preparation and grocery shopping, with women engaging in these household activities more often than men. Additionally, these authors noted that male patients are more likely to be actively supported by their wives in the form of meal preparation and verbal encouragement, whereas female patients are only passively supported by their husbands. In another study, it was noted that adherence to dietary advice was higher in males than in females among type 2 diabetic patients. ${ }^{6}$ However, sex should not be treated as an isolated determinant of adherence to dietary recommendations. That would be an oversimplification. Discrepancies in the context of sex can suggest the need to take into account additional mediating factors in the relation between sex and adherence to dietary recommendations. The level of one's own disease acceptance has not been noted as a mediating factor between sociodemographic variables (eg, education, place of residence, and monthly income) and the patient's adherence to dietary recommendations.

In the case of some medical variables (dietitian care, method of treatment, and complication), a mediation effect of the disease acceptance level on the relationship between regular blood glucose testing and adherence to dietary recommendations was not observed.

A change in the diet involves greater patient engagement and introducing changes in lifestyle that are not necessarily accepted by the patient. For example, patients do not want to give up consuming foods that they truly enjoy but which should be excluded. ${ }^{22}$ A lack of correlation with the number of complications may be explained by a lack of patient awareness that the disease symptoms that they experience are directly connected with their disease development. For example, Al-Rasheedi ${ }^{31}$ reported that about $15.6 \%$ of patients were not aware of diabetic complications at all and $13.8 \%$ were aware of one complication. The absence of a link with a method of treatment may be connected to the fact that a patient may believe that the doctor is responsible for effective treatment. Therefore, patients transfer the responsibility for treatment to the doctor. ${ }^{7}$

The above-mentioned results demonstrate that adaptation to one's own disease acceptance and undertaking effective forms of treatment are complex processes. One's own disease acceptance may be a vital factor in the process, but it is not a decisive variable conditioning a positive outcome of the adaptation process. This is demonstrated by the fact that acceptance of the disease is a weak mediator of this relationship. This suggests a need for further empirical studies aimed at identifying factors enhancing effective adherence to dietary recommendations in diabetic patients. An adequate level of social support and dietary education, provided not only to the patient but also to his or her closest environment, can be one of those factors. It would also be interesting to try to evaluate the AADQ as an independent determinant of adherence to the recommended diet in the presence of other well-known influential determinants (eg, patient-physician relationship, impulsivity, self-efficacy, motivation).

The results of this study are not free of limitations. Administration of an original instrument to evaluate adherence to dietary recommendations is an important limitation. Nevertheless, the instrument was developed using current guidelines on dietary treatment in diabetes. Notwithstanding, the translated measure of the AADQ, which is a core variable in this study, was characterized by relatively low internal consistency. Therefore, further studies should be conducted to enable more accurate verification of the reliability and accuracy of the developed research tool. The number of subjects and the use of crossover studies are other important limitations. The specific patient group, which performed glycemic control more frequently in comparison with groups in other studies, is a considerable limitation of this study. 


\section{Conclusion}

The disease acceptance level has only a minor mediation effect on the relationship between regular blood glucose testing and adherence to dietary recommendations. In the case of sociodemographic variables (sex, education level, place of residence, and monthly income) and some medical variables (dietitian care, method of treatment, and complication), this mediation effect was not observed. The results of the study suggest that the disease acceptance level is not the main factor mediating the relationship between regular blood glucose testing and adherence to dietary recommendations. The attitude toward one's own disease does not guarantee undertaking adequate forms of treatment, such as adherence to dietary recommendations. Therefore, additional mediators in the relationship should be looked for.

\section{Disclosure}

The authors report no conflicts of interest in this work.

\section{References}

1. American Diabetes Association. Standards of medical care in diabetes 2016. Diabetes Care. 2016;39(Suppl 1):S1-S109.

2. International Diabetes Federation. IDF diabetes atlas 2015. Available from: http://www.diabetesatlas.org/. Accessed December 11, 2017.

3. Ingelfinger JR, Jarcho JA. Increase in the incidence of diabetes and its implications. N Engl J Med. 2017;376(15):1473-1474.

4. Breeze PR, Thomas C, Squires H, et al. Cost-effectiveness of population-based, community, workplace and individual policies for diabetes prevention in the UK. Diabet Med. 2017;34(8):1136-1144.

5. Franz MJ, MacLeod J, Evert A, et al. Academy of Nutrition and Dietetics nutrition practice guideline for type 1 and type 2 diabetes in adults: systematic review of evidence for medical nutrition therapy effectiveness and recommendations for integration into the nutrition care process. J Acad Nutr Diet. 2017;117(10):1659-1679.

6. Ahola AJ, Groop PH. Barriers to self-management of diabetes. Diabet Med. 2013;30(4):413-420.

7. Jaworski M, Adamus MM. Health suggestibility, optimism and sense of responsibility for health in diabetic patients. Int J Diabetes Dev Ctries. 2016;36(3):290-294.

8. Hyphantis T, Katsoudas S, Voudiclari S. Ego mechanisms of defense are associated with patients' preference of treatment modality independent of psychological distress in end-stage renal disease. Patient Prefer Adherence. 2010;4:25-32.

9. Cramer P. Defense mechanisms in psychology today. Further processes for adaptation. Am Psychol. 2000;55(6):637-646.

10. Gupta L, Khandelwal D, Singla R, Gupta P, Kalra S. Pragmatic dietary advice for diabetes during Navratris. Indian J Endocrinol Metab. 2017; 21(1):231-237.

11. Evert AB, Boucher JL, Cypress M, et al. Nutrition therapy recommendations for the management of adults with diabetes. Diabetes Care. 2013;36(11):3821-3842.

12. Esmaeilinasab M, Ebrahimi M, Mokarrar MH, Rahmati L, Mahjouri MY, Arzaghi SM. Type II diabetes and personality: a study to explore other psychosomatic aspects of diabetes. J Diabetes Metab Disord. 2016;15:54.

13. Sloan FA, Padron NA, Platt AC. Preferences, beliefs, and selfmanagement of diabetes. Health Serv Res. 2009;44(3):1068-1087.

14. Daly JM, Hartz AJ, Xu Y, et al. An assessment of attitudes, behaviors, and outcomes of patients with type 2 diabetes. J Am Board Fam Med. 2009; 22(3):280-290.
15. Petersen S, van den Berg RA, Janssens T, Van den Bergh O. Illness and symptom perception: a theoretical approach towards an integrative measurement model. Clin Psychol Rev. 2011;31(3):428-439.

16. Anderson RM, Donnelly MB, Dedrick RF. Measuring the attitudes of patients towards diabetes and its treatment. Patient Educ Couns. 1990; 16(3):231-245.

17. Simon-Tuval T, Shmueli A, Harman-Boehm I. Adherence to self-care behaviors among patients with type 2 diabetes: the role of risk preferences. Value Health. 2016;19(6):844-851.

18. Schmitt A, Reimer A, Kulzer B, Haak T, Gahr A, Hermanns N. Assessment of diabetes acceptance can help identify patients with ineffective diabetes self-care and poor diabetes control. Diabet Med. 2014;31(11):1446-1451.

19. Polskie Towarzystwo Diabetologiczne. Zalecenia kliniczne dotyczące postępowania u chorych na cukrzycę 2015. Diabetologia kliniczna. 2015;4(Supplement A):1-73.

20. MacLeod J, Franz MJ, Handu D, et al. Academy of Nutrition and Dietetics nutrition practice guideline for type 1 and type 2 diabetes in adults: nutrition intervention evidence reviews and recommendations. $J$ Acad Nutr Diet. 2017;117(10):1637-1658.

21. Cohen J, Cohen P, West SG, Aiken LS. Applied Multiple Regression/ Correlation Analysis for the Behavioral Sciences. Mahwah, NJ: Routledge; 2013.

22. McElfish PA, Bridges MD, Hudson JS, et al. Family model of diabetes education with a Pacific islander community. Diabetes Educ. 2015; 41(6):706-715.

23. Coppell KJ, Kataoka M, Williams SM, Chisholm AW, Vorgers SM, Mann JI. Nutritional intervention in patients with type 2 diabetes who are hyperglycaemic despite optimised drug treatment - Lifestyle Over and Above Drugs in Diabetes (LOADD) study: randomised controlled trial. BMJ. 2010;341:c3337.

24. Alssema M, Boers HM, Ceriello A, et al. Diet and glycaemia: the markers and their meaning. A report of the Unilever Nutrition Workshop. Br J Nutr. 2015;113(2):239-248.

25. Nowlin SY, Hammer MJ, D'Eramo Melkus G. Diet, inflammation, and glycemic control in type 2 diabetes: an integrative review of the literature. J Nutr Metab. 2012;2012:article ID 542698.

26. Yokoyama Y, Barnard ND, Levin SM, Watanabe M. Vegetarian diets and glycemic control in diabetes: a systematic review and meta-analysis. Cardiovasc Diagn Ther. 2014;4(5):373-382.

27. Shao Y, Liang L, Shi L, Wan C, Yu S. The effect of social support on glycemic control in patients with type 2 diabetes mellitus: the mediating roles of self-efficacy and adherence. J Diabetes Res. 2017; 2017:2804178.

28. Kamody RC, Berlin KS, Rybak TM, et al. Psychological flexibility among youth with type 1 diabetes: relating patterns of acceptance, adherence, and stress to adaptation. Behav Med. 2017:1-9.

29. Popa-Velea O, Bubulac L, Petrescu L, Purcarea RM. Psychopathology and psychotherapeutic intervention in diabetes: particularities, challenges, and limits. J Med Life. 2016;9(4):328-333.

30. DuBois CM, Millstein RA, Celano CM, Wexler DJ, Huffman JC. Feasibility and acceptability of a positive psychological intervention for patients with type 2 diabetes. Prim Care Companion CNS Disord. 2016;18(3):Epub.

31. Al-Rasheedi AA. The role of educational level in glycemic control among patients with type ii diabetes mellitus. Int J Health Sci. 2014; $8(2): 177-187$.

32. Kjome RL, Granas AG, Nerhus K, Roraas TH, Sandberg S. The prevalence of self-monitoring of blood glucose and costs of glucometer strips in a nationwide cohort. Diabetes Technol Ther. 2010;12(9):701-705.

33. Austin S, Senecal C, Guay F, Nouwen A. Effects of gender, age, and diabetes duration on dietary self-care in adolescents with type 1 diabetes: a self-determination theory perspective. J Health Psychol. 2011; 16(6):917-928.

34. Wong M, Gucciardi E, Li L, Grace SL. Gender and nutrition management in type 2 diabetes. Can J Diet Pract Res. 2005;66(4):215-220. 


\section{Supplementary material}

Instructions: please complete the following questions to reflect your opinions as accurately as possible and to answer factual questions to the best of your knowledge.

Your information will be kept confidential.

Please select only one answer for each question.

1. How many meals do you usually eat during the day?

\begin{tabular}{|l|l|l|l|l|l|l|}
\hline 1 meal & 2 meals & 3 meals & 4 meals & 5 meals & 6 meals & 7 meals or more \\
\hline$\square$ & $\square$ & $\square$ & $\square$ & $\square$ & $\square$ & $\square$ \\
\hline
\end{tabular}

2. Do you usually eat meals at the same times?

(1) - Yes

(2) _ No

3. What are the most frequent time intervals between meals?

\begin{tabular}{|l|l|l|l|}
\hline$<3$ hours & $3-4$ hours & $5-6$ hours & $>6$ hours \\
\hline$\square$ & $\square$ & $\square$ & $\square$ \\
\hline
\end{tabular}

4. Do you add sugar to hot drinks, such as tea, cocoa, or coffee?

(1) _ Yes

(2) _ No

5. What kind of bread do you usually eat?

(1) _ Rye bread, wholemeal, whole grain

(2) _ White bread, Vienna roll

(3) _ I do not eat bread.

6. What kind of cereal products (eg, cereal, pasta) do you usually eat?

(1) _ Coarse-grained cereals (eg, buckwheat, pearl barley), wholemeal pasta, brown rice

(2) _ Non-coarse-grained cereals, such as semolina and couscous, non-wholemeal pasta and white rice

(3) _ I do not eat this type of product.

7. What kind of milk and dairy product do you usually eat?

(1) _ High-fat dairy products (eg, cottage cheese, cheese, sour cream, processed cheese), whole milk, or reduced-fat milk (2\%)

(2) _ Low-fat dairy products (eg, low-fat cottage cheese, natural yogurt, kefir, buttermilk), low-fat milk (1\%), or fat-free milk

(3) _ I do not eat this type of product.

8. What kind of meat do you usually eat?

(1) _ Chicken, turkey, rabbit

(2) _ Red meat such as pork, beef, veal, lamb, and wild meat

(3) _ I do not eat this type of product.

9. What kind of fat do you usually use to prepare meals?

(1) _ Butter

(2) _ Lard

(3) __ Oils (eg, rapeseed oil, olive oil)

(4) _ Margarine

(5) _ I do not use this type of product to prepare meals.

10. What kind of fat do you usually eat with bread (eg, as a sandwich)?

(1) _ Butter

(2) _ Margarines

(3) _ Mix of butter, oils, and margarines

(4) _ I do not use any fat on bread.

11. How often do you eat...

\begin{tabular}{|l|l|l|l|l|l|l|}
\hline Products & Never & $\begin{array}{l}1-3 \text { times } \\
\text { a month }\end{array}$ & $\begin{array}{l}\text { Once a } \\
\text { week }\end{array}$ & $\begin{array}{l}\text { A few times } \\
\text { a week }\end{array}$ & $\begin{array}{l}\text { Once } \\
\text { a day }\end{array}$ & $\begin{array}{l}\text { Several } \\
\text { times a day }\end{array}$ \\
\hline a) Vegetables? & & & & & & \\
\hline
\end{tabular}

Figure SI (Continued) 


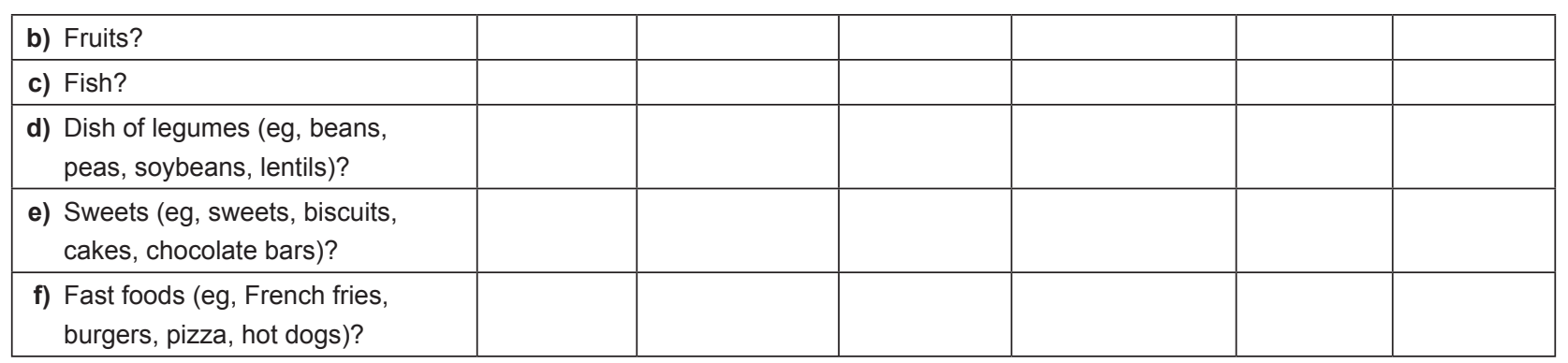

12. How many eggs do you usually eat per week?

\begin{tabular}{|l|l|l|l|l|l|}
\hline 1 & 2 & 3 & 4 & 5 or more & I do not eat this type of product \\
\hline$\square$ & $\square$ & $\square$ & $\square$ & $\square$ & $\square$ \\
\hline
\end{tabular}

13. How often do you drink...

\begin{tabular}{|l|l|l|l|l|l|l|}
\hline Products & Never & $\begin{array}{l}1-3 \text { times } \\
\text { a month }\end{array}$ & $\begin{array}{l}\text { Once a } \\
\text { week }\end{array}$ & $\begin{array}{l}\text { A few times } \\
\text { a week }\end{array}$ & $\begin{array}{l}\text { Once } \\
\text { a day }\end{array}$ & $\begin{array}{l}\text { Several } \\
\text { times a day }\end{array}$ \\
\hline a) Water? & $\square$ & $\square$ & $\square$ & $\square$ & $\square$ & $\square$ \\
\hline b) Alcohol? & $\square$ & $\square$ & $\square$ & $\square$ & $\square$ & $\square$ \\
\hline $\begin{array}{l}\text { c) Soft drinks such as Coca-Cola, } \\
\text { Pepsi, Sprite, Fanta, orange } \\
\text { soda, or lemonade? }\end{array}$ & $\square$ & $\square$ & $\square$ & $\square$ & $\square$ & $\square$ \\
\hline
\end{tabular}

\section{KEY}

\begin{tabular}{|c|c|c|}
\hline Question & The answer that gets the points & Point \\
\hline 1 & $\begin{array}{l}\text { (4) } 4 \text { meals } \\
\text { (5) } 5 \text { meals } \\
\text { (6) } 6 \text { meals }\end{array}$ & 1 \\
\hline 2 & (1) Yes & 1 \\
\hline 3 & (2) 3-4 hours & 1 \\
\hline 4 & (2) No & 1 \\
\hline 5 & (1) Rye bread, wholemeal, whole grain & 1 \\
\hline 6 & (1) Coarse-grained cereals (eg, buckwheat, pearl barley), wholemeal pasta, brown rice & 1 \\
\hline 7 & $\begin{array}{l}\text { (2) Low-fat dairy products (eg, low-fat cottage cheese, natural yogurt, kefir, buttermilk), } \\
\text { low-fat milk (1\%), or fat-free milk }\end{array}$ & 1 \\
\hline 8 & (1) Chicken, turkey, rabbit & 1 \\
\hline 9 & (3) Oils (eg, rapeseed oil, olive oil) & 1 \\
\hline 10 & $\begin{array}{l}\text { (2) Margarines } \\
\text { (4) I do not use any fat on bread }\end{array}$ & 1 \\
\hline \multicolumn{3}{|l|}{11} \\
\hline a) & (6) Several times a day & 1 \\
\hline b) & (6) Several times a day & 1 \\
\hline c) & $\begin{array}{l}\text { (3) Once a week } \\
\text { (4) A few times a week }\end{array}$ & 1 \\
\hline d) & $\begin{array}{l}\text { (3) Once a week } \\
\text { (4) A few times a week } \\
\text { (5) Once a day } \\
\text { (6) Several times a day }\end{array}$ & 1 \\
\hline e) & $\begin{array}{l}\text { (1) Never } \\
\text { (2) } 1-3 \text { times a month }\end{array}$ & 1 \\
\hline f) & $\begin{array}{l}\text { (1) Never } \\
\text { (2) } 1-3 \text { times a month }\end{array}$ & 1 \\
\hline
\end{tabular}

Figure SI (Continued) 


\begin{tabular}{|l|l|l|}
\hline 12 & \begin{tabular}{l}
$(1)-1$ \\
$(2)-2$ \\
\multicolumn{1}{|l|}{$(3)-3$} \\
\multicolumn{1}{|l|}{$(4)-4$}
\end{tabular} & 1 \\
\hline 13 & (6) Several times a day & 1 \\
\hline a) & (1) Never & 1 \\
\hline b) & (1) Never & 1 \\
\hline c) & (2) $1-3$ times a month & \\
\hline
\end{tabular}

Figure SI Patient diet adherence in diabetes (PDAD).

Notes: The original questionnaire is in Polish. The authors of the Polish version are the authors of this paper. For the purposes of this publication, it has been translated by the authors of this paper into English.

\section{Publish your work in this journal}

Patient Preference and Adherence is an international, peer-reviewed, open access journal that focuses on the growing importance of patient preference and adherence throughout the therapeutic continuum. Patient satisfaction, acceptability, quality of life, compliance, persistence and their role in developing new therapeutic modalities and compounds to optimize clinical outcomes for existing disease states are major areas of interest for the journal. This journal has been accepted for indexing on PubMed Central. The manuscript management system is completely online and includes a very quick and fair peer-review system, which is all easy to use. Visit http://www dovepress.com/testimonials.php to read real quotes from published authors.

Submit your manuscript here: http://www.dovepress.com/patient-preference-and-adherence-journal 